\title{
LAS PANDEMIAS EN EL CINE: ARGUMENTOS QUE SE HAN HECHO VIRALES
}

\section{Pandemies in Cinema: Arguments that Have Gone Viral}

\author{
Juan A. JUANES MÉNDEZ \\ Facultad de Medicina. Universidad de Salamanca (España). \\ Correo electrónico: jajm@usal.es
}

Fecha de recepción: 19 de mayo de 2020

Fecha de aceptación: 28 de julio de 2020

Fecha de publicación: 29 de enero de 2021

\section{Resumen}

Las pandemias siempre han sido una de las grandes preocupaciones de la humanidad dado que en algún momento de la historia han azotado a la población mundial.

La situación actual generada por el coronavirus, ha hecho que las películas sobre infecciones, epidemias, pandemias, etc., hayan sido las más visionadas en diferentes plataformas de streaming, debido al confinamiento que hemos tenido que padecer. Este trabajo pretende hacer una visión general de las principales y más llamativas películas que tratan sobre distintos aspectos de patologías por contagios virales. Este tipo de películas siempre ha mostrado gran interés en la población, siendo por lo general muy rentables económicamente para las productoras cinematográficas. Con la visualización de estas películas se busca contribuir, a una sensibilización de la población mundial y poder difundir y promover medidas higiénico-sanitarias.

Palabras clave: pandemia; cine; prevención.

\section{Abstract}

Pandemics have always been one of the great concerns of humanity since at some point in history they have plagued the world population.

The current situation due to by the coronavirus, has made the films about infections, epidemics, pandemics, etc., have been the most viewed on different streaming platforms, 
due to the confinement we have had to suffer. This paper aims to make an overview of the main and most striking films that deal with different aspects of viral infection pathologies. This type of film has always shown great interest in the population, being generally very profitable economically for films production companies. The aim of these films is to contribute to raising the awareness of the world population and to be able to disseminate and promote hygienicsanitary measures.

Keywords: pandemic; films; prevention.

\section{LAS PANDEMIAS A LO LARGO DE LA HISTORIA}

La evolución biológica de la especie humana, así como los cambios en los patrones de conducta han desarrollado un gran impacto en la evolución y generación de nuevas enfermedades ${ }^{1}$. Es evidente que la humanidad ha evolucionado muy rápidamente, encontrándonos en un mundo cambiante en diversos aspectos como por ejemplo el gran crecimiento poblacional, el desarrollo económico y el progreso de nuevas tecnologías, etc. $^{2}$. Pero además de lo dicho anteriormente, otras muchas causas han llevado a la humanidad a contraer enfermedades infectocontagiosas, entre ellas podemos destacar la pobreza, la migración de la población, el bioterrorismo, el desplazamiento de poblaciones, el comportamiento sexual, el consumo de drogas entre otras muchas causas ${ }^{3}$.

El vertiginoso progreso en la generación de antibióticos y vacunas, sobre todo durante la primera mitad del siglo XX, llevó a pensar que se había llegado a cerrar el capítulo de las enfermedades infecciosas y declarar así ganada la guerra contra esas enfermedades infeccionas. Sin embargo, como muy bien señala la Organización Mundial de la Salud (OMS), la guerra entre los seres humanos y los microorganismos patógenos continúa todavía y no está claro quién será el ganador ${ }^{4}$.

Hasta la fecha actual se han producido más de veinte epidemias y pandemias que han afectado enormemente a la humanidad ${ }^{5,6}$. Desde la más antigua conocida por el año 430 a.C. hasta la más actual producida por el coronavirus, aparecida en China en 2019.
Las civilizaciones más antiguan pensaban que estas enfermedades surgían por un castigo de los dioses.

Una de las más llamativas patologías fue la viruela, una enfermedad tan antigua que data de las poblaciones humanas del año $10000 \mathrm{a}$. C.

Por el año 1918 surgió la famosa gripe española, que apareció en Europa a través de Francia, al finalizar la segunda guerra mundial. Extendiéndose por Reino Unido, Alemania, Italia, y finalmente entró en España.

Más recientemente en 1981 se descubrió en Estados Unidos el virus del Sida, cuya procedencia fue relacionada con los simios y chimpancés que habrían entrado en contacto con el hombre en la década de 1920, en el centro de África.

En este siglo XXI, el SARS en el sudeste asiático, el ébola en África, el MERS en Medio Oriente y la gripe A (H1N1) en todo el mundo, han sido epidemias y pandemias que han puesto en jaque a la comunidad científica internacional; siendo la más reciente pandemia en la historia, es por la que estamos atravesando, y corresponde al coronavirus COVID-19 que se originó en la ciudad china de Wuhan y que actualmente está presente en los cinco continentes.

Aunque las respuestas a las más recientes epidemias y pandemias virales han sido básicamente reactivas, cada día se tienen mejores conocimientos y medios científicos para adoptar estrategias proactivas que permitan prevenir o al menos contener los brotes epidémicos en sus inicios, antes de que los mismos adquieran proporciones más severas.

La historia cinematográfica de películas que reflejan estos argumentos de patologías víricas, 
bacterianas, o de cualquier tipo de microorganismo patógeno, no es más que un reflejo de las constantes transformaciones tecnológicas, sociales, políticas, culturales, y sanitarias que a lo largo de los tiempos se han dado y se seguirán dando en la población. Por ello, como sabemos el cine de ficción ya pronosticó la llegada de pandemias en el mundo. Ese miedo a sufrir una epidemia o una pandemia ha hecho que la industria del cine utilice en sus argumentos esta temática como una garantía de éxito en los espectadores. Por eso son muchas las películas que nos acercan a ese escenario catastrófico en el que un virus amenaza nuestra existencia, es éste el protagonista de toda la acción y argumento de la película. En las circunstancias actuales varias de estas películas han superado récords de visualización en estos días, valiendo en estos momentos, más que nunca, la expresión de que "se han hecho virales".

\section{UN PASEO POR LAS PRINCIPALES PELÍCULAS}

Las pandemias han tenido una repercusión importante dentro del mundo del cine. Existen muchas películas de este género, siendo algunas más realistas, con situaciones dramáticas en las que un virus amenaza la salud mundial y donde los protagonistas luchan por encontrar una cura. Pero también existen películas más fantasiosas, con zombies o alienígenas formando parte de la trama.

Llevaremos a cabo un repaso por las películas más significativas que la industria cinematográfica ha difundido. Con ello se busca promover y concienciar a la población en general a tomar determinadas actitudes ante patologías severas provocadas por microorganismos, no fáciles de controlar. Además, con la presentación de estas películas lo que se pretende, no es meter miedo a la población, sino provocar al espectador un respeto y cuidado antes enfermedades de estas características.
Describiremos una selección de películas de esta trama relacionada con estas patologías.

\section{Pánico en las calles}

Una de las primeras películas con una trama sobre la peste neumónica, fue Pánico en las calles / Panic in the streets (1950) (Foto 1), de Elia Kazan. Galardonada con un Oscar a la mejor historia, la película cuenta como una noche, en los barrios bajos de Nueva Orleáns, el rufián Blackie y sus amigos matan a un inmigrante que les había ganado jugando al póker. A la mañana siguiente, el doctor Clint Reed del Servicio de Salud Pública confirma que el muerto tenía la peste neumónica. Para evitar una epidemia que tendría efectos catastróficos, Clint y el capitán de policía Tom Warren tratan de encontrar y aislar a los asesinos. La operación se lleva a cabo en secreto, por miedo a que la población sea presa del pánico.

Título original: Panic in the streets.

País: Estados Unidos.

Año: 1950.

Director: Elia Kazan.

Música: Alfred Newman.

Fotografía: Joseph MacDonald.

Montaje: Harmon Jones.

Guion: Richard Murphy, Daniel Fuchs.

Intérpretes: Richard Widmark, Paul Douglas, Barbara Bel Geddes, Jack Palance, Zero Mostel.

Duración: 96 minutos.

Idioma original: inglés.

Género: thriller.

Productoras: 20th Century Fox.

Sinopsis: La película, de crimen y suspense americano, se desarrolla en las zonas humildes de la ciudad Nueva Orleáns. En estos barrios durante la noche Blackie y sus amigos asesinan a un inmigrante marinero, de origen armenio, que entró ilegalmente en Estados Unidos y que les había ganado jugando al póker. Cuando el doctor Clint Reed del Servicio de Salud Pública analiza el cadáver del 


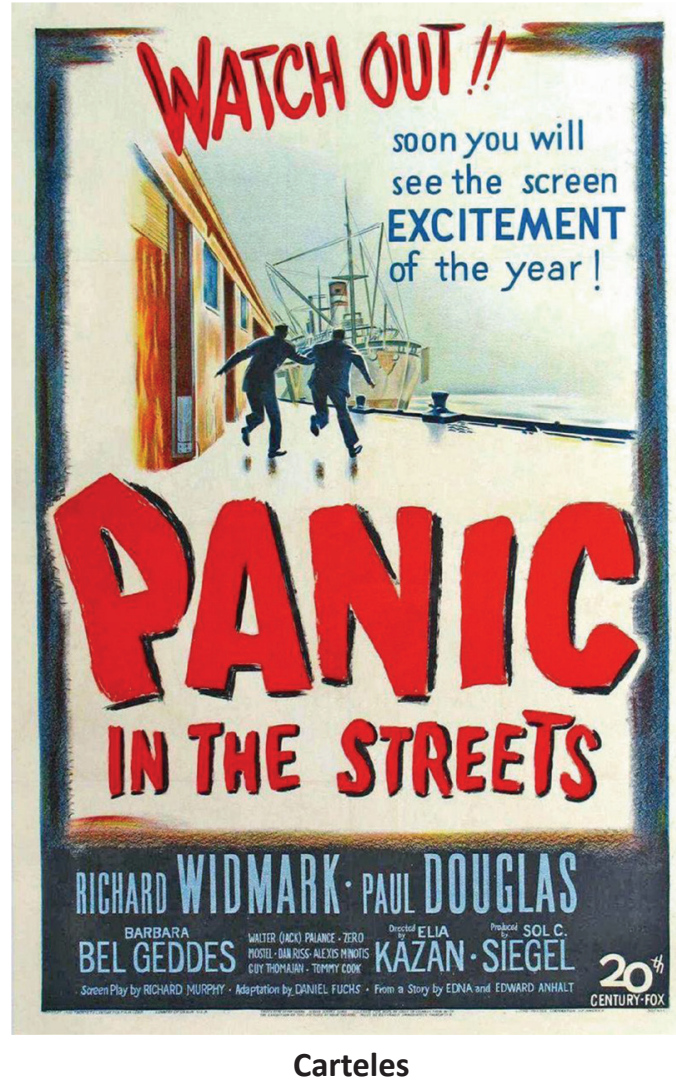

indigente observa que el muerto presentaba la peste bubónica; enfermedad de graves consecuencias y con muy alta posibilidad de contagio entre la población. La película se centra en la búsqueda y aislamiento de los asesinos, para poder evitar una epidemia que tendría sin duda efectos catastróficos. Clint y el capitán de policía Tom Warren lideran esa operación de búsqueda y captura, en secreto, para no alarmar a la población sea presa del pánico. El tiempo corre en su contra, por lo que deberán logar su objetivo en tan solo dos días. La película mezcla la investigación médica con la policíaca.

Enlaces:

https://www.imdb.com/title/tt0042832/ Tráiler

\section{El día del apocalipsis}

Ha sido en las últimas dos décadas cuando han proliferado el número de películas con tramas relacionadas con virus, pandemias, infecciones.

Una de las películas que ha gozado de gran aceptación fue The Crazies / El día del apocalipsis (2010) de Breck Eisner (Foto 2). La trama de esta película se basa en la afectación del suministro de agua infectado con el virus "Trixie». Una misteriosa toxina convierte a la gente en asesinos sin escrúpulos. Cuando una ciudad empieza a sucumbir a la plaga, el Ejército bloquea los accesos a la misma, aislando a los pocos ciudadanos no infectados y dejándolos a merced de los asesinos.

Título original: The Crazies.

País: Estados Unidos.

Año: 2010.

Director: Breck Eisner.

Música: Mark Isham.

Fotografía: Maxime Alexandre.

Montaje: Billy Fox.

Guion: Scott Kosar, Ray Wright, George A. Romero.

Intérpretes: Timothy Olyphant, Radha Mitchell, Joe Anderson, Danielle Panabaker.

Duración: 101 minutos.

Idioma original: inglés.

Género: terror.

Productoras: Overture Films, Participant Media, Imagenation Abu Dhabi.

Sinopsis: Una misteriosa toxina en el agua convierte a cualquiera que esté expuesto a ella en un asesino sin escrúpulos. Los residentes de un pequeño pueblo agrícola empiezan a sucumbir a un desenfreno incontrolable de violencia y la escalofriante masacre acaba en una sanguinaria anarquía. En un intento por controlar la epidemia, el ejército envía una fuerza de élite a bloquear los accesos a la ciudad, aislando a los pocos ciudadanos no infectados que quedan y dejándolos 


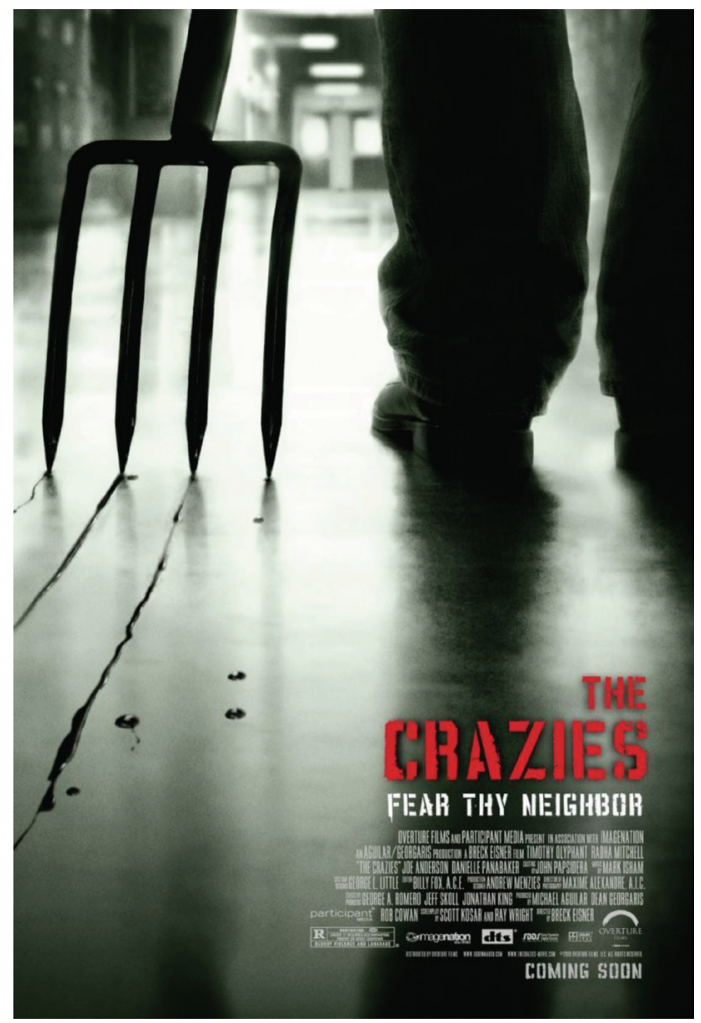

a merced de los despiadados asesinos que acechan en la oscuridad.

\section{Enlaces:}

$$
\begin{gathered}
\text { https://www.imdb.com/title/tt0455407/ } \\
\text { Tráiler }
\end{gathered}
$$

\section{Infectados (Carriers)}

La película estadounidense, Carriers / Infectados (2010) de Àlex Pastor y David Pastor (Foto 3), narra cómo cuatro personas huyen en un automóvil víctimas de una pandemia viral. Durante el transcurso de la película estas cuatro personas jóvenes quieren intentar llegar a una playa del Golfo de México para aislarse y tratar de sobrevivir lo peor de la pandemia. Pero les espera un viaje bastante largo, y la situación se pone cada vez más difícil. A lo largo del viaje encontrarán

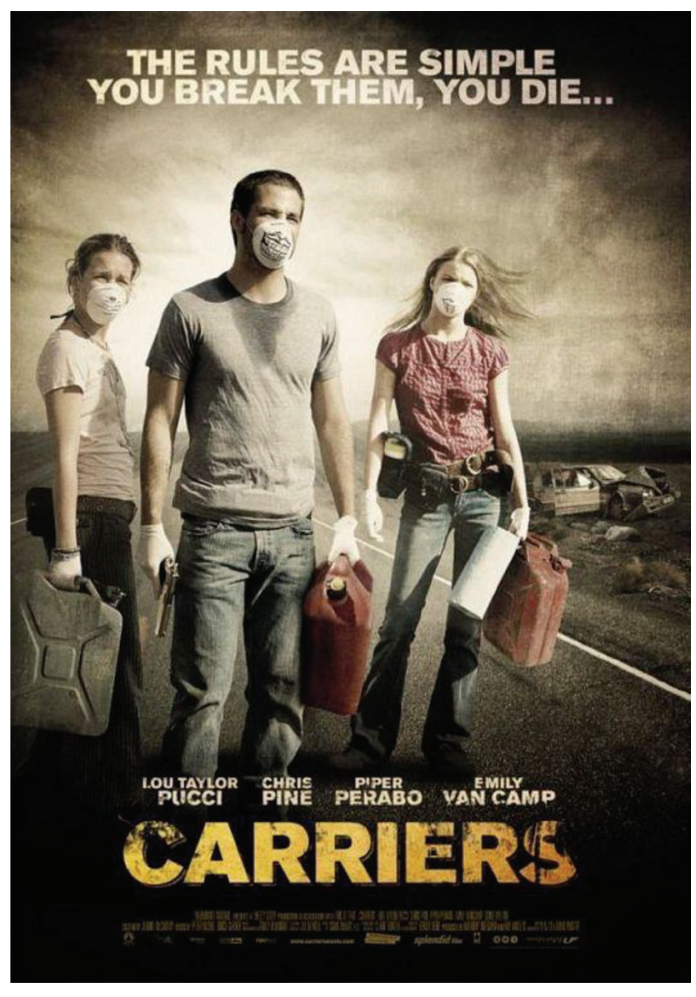

personas infectadas, médicos que han perdido la cabeza al no poder afrontar la situación.

Título original: Carriers.

País: Estados Unidos.

Año: 2009.

Director: Àlex Pastor, David Pastor.

Música: Joel McNeely.

Fotografía: Benoît Debie.

Montaje: Craig McKay.

Guion: Àlex Pastor, David Pastor.

Intérpretes: Piper Perabo, Chris Pine, Lou Taylor Pucci, Emily VanCamp, Christopher Meloni, Jan Cunningham.

Duración: 81 minutos.

Idioma original: inglés.

Género: terror.

Productoras: Paramount Vantage, Likely Story, This Is That Productions. 
Sinopsis: Un virus mortal se extiende por toda la Tierra matando a gran parte de la población. Cuatro jóvenes, que todavía no han sido infectados, se dirigen a una apartada playa del Golfo de México con la intención de refugiarse hasta que pase la epidemia. Su principal temor es encontrarse en su camino con otros humanos que les puedan contagiar. Así, cuando su coche se estropea en una carretera aislada, empezará una desesperada lucha por la supervivencia en la que no sólo deberán enfrentarse a niños infectados, médicos homicidas o saqueadores sin escrúpulos sino, sobre todo, a la creciente desconfianza que surge entre ellos.

Enlaces:

https://www.imdb.com/title/tt0806203/

http://www.sensacine.com/peliculas /pelicula-141844/

Tráiler

\section{Contagio}

Contagio / Contagion (2011), de Steven Soderbergh, (Foto 4); se basa en la pandemia de gripe $A(H 1 N 1)$. La película narra el regreso de una mujer a Minnesota tras un viaje de negocios a Hong Kong. Ella le atribuye su malestar al cambio de horario; sin embargo, tan solo dos días después, muere y los médicos le dicen a su esposo que no saben la causa de su muerte. Pronto, otras personas empiezan a mostrar los mismos síntomas y surge una pandemia. Los médicos intentan contener al agente letal, pero la sociedad empieza a colapsarse cuando los fanáticos de una bloguera provocan una paranoia.

Título original: Contagion.

País: Estados Unidos.

Año: 2011.

Director: Steven Soderbergh.

Música: Cliff Martínez.

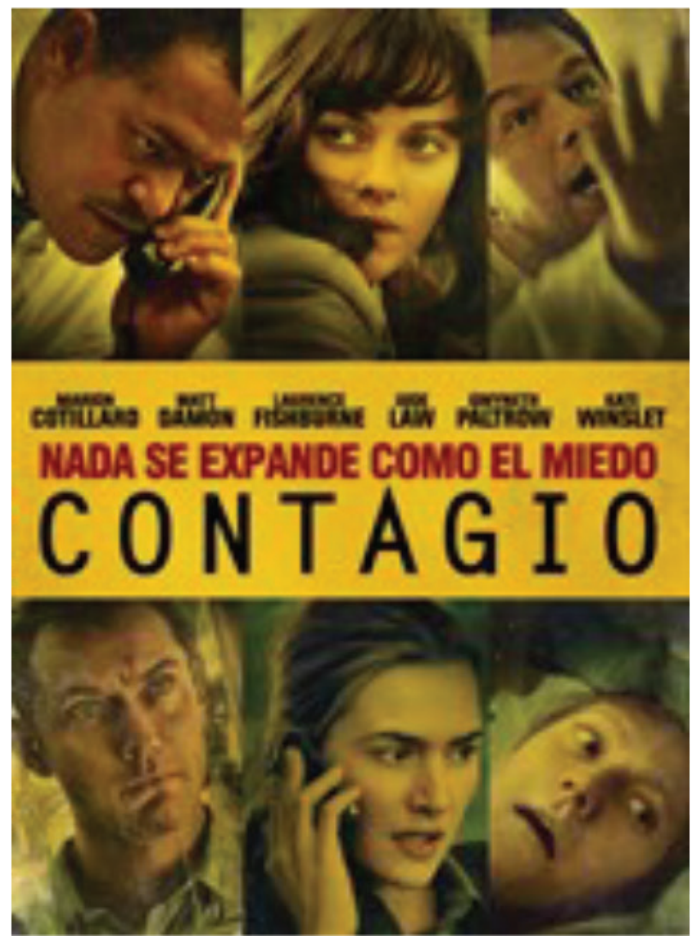

Fotografía: Peter Andrews (seudónimo del propio director).

Montaje: Stephen Mirrione.

Guion: Scott Z. Burns.

Intérpretes: Marion Cotillard, Matt Damon, Kate Winslet, Laurence Fishburne.

Duración: 106 minutos.

Idioma original: inglés.

Género: drama. Suspense, thiller.

Productoras: Warner Bros., Participant, Imagenation Abu Dhabi FZ, Double Feature Films, Digital Image Associates, Regency Enterprises.

Sinopsis: Beth acaba de volver de un viaje de negocios en Hong Kong. Afectada por tos y jaquecas constantes, pronto enferma gravemente y muere. Rápidamente casos similares comienzan a asolar todo el mundo. Los síntomas de Beth se agravan y dos días después colapsa. Su marido, Mitch intenta llevarla al hospital, pero fallece. Mitch regresa a casa 
para ver que su hijo también murió. Mitch es puesto en cuarentena, pero descubre que es inmune a la infección. La Seguridad Social de Atlanta trata de buscar una vacuna para combatir al virus.

Enlaces:

$$
\begin{gathered}
\text { https://www.imdb.com/title/tt1598778/ } \\
\text { Tráiler }
\end{gathered}
$$

Virus

Sin duda, una de las que más visionados ha tenido, sobre todo en estos días de confinamiento que hemos tenido, es la película coreana titulada Virus / Gamgi (2013) de Kim Sung-su (Foto 5). La película presenta un drama social, y las consecuencias de la inacción gubernamental en situaciones de emergencia. Esta película se basa en la proliferación del virus Influenza A subtipo H5N1 que mata a sus víctimas en 2 semanas, sembrando el caos en la población de Corea del Sur.

Título original: Gamgi.

País: Corea del Sur.

Año: 2013.

Director: Sung-su Kim.

Música: Tae-seong Kim.

Fotografía: Mo-gae Lee.

Montaje: Na-young Nam.

Guion: Young-jong Lee,Sung-soo Kim, Jae-ho Jung.

Intérpretes: Jang Hyuk, Su-Ae, Cha In-pyo, Park Hyo-ju, Lee Hee-jun, Lee Sang-yeob, Andrew William Brand.

Duración: 122 minutos.

Género: acción, drama, ciencia ficción.

Productoras: iLoveCinema, iFilm Co.

Idioma: coreano.

Sinopsis: "La peor epidemia jamás vista está arrasando Bundang, un suburbio de Seúl. Después de introducir a una serie de inmigrantes ilegales en el país, Byung-woo muere a causa de un virus desconocido. Poco después, los mismos síntomas aparecen en otros

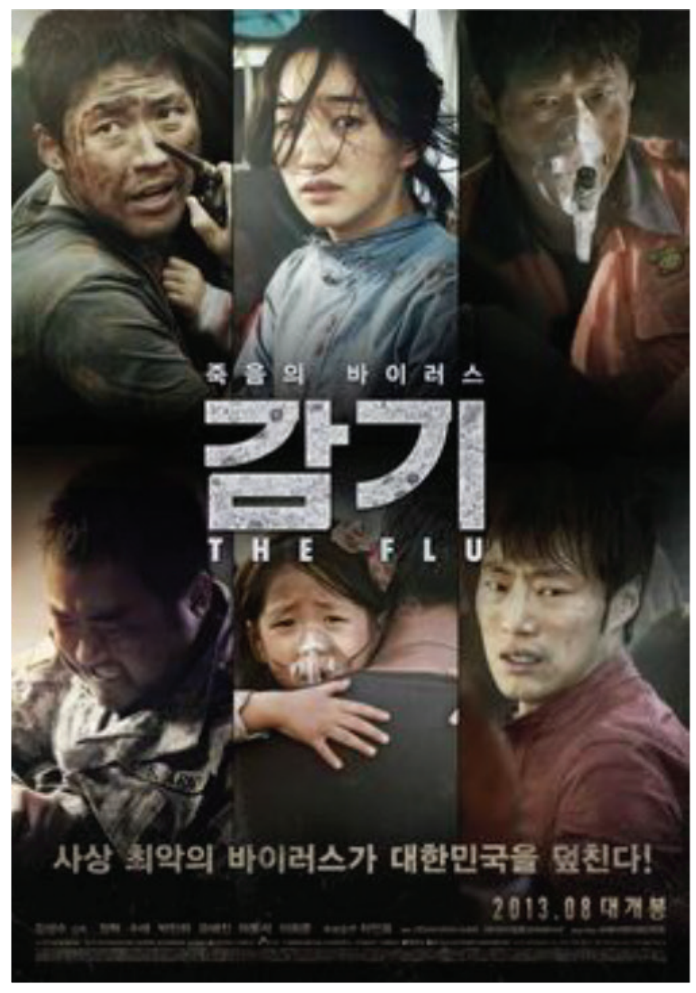

residentes de la zona. El pueblo se siente indefenso ante un virus que se transmite por el aire y en el que el número de afectados crece rápidamente, desatando el caos. Tratando de evitar la peor de las previsiones, la ciudad, en la que viven más de 19 millones de habitantes, se prepara para cerrar por completo sus fronteras por órdenes del gobierno. Mientras tanto, el especialista vírico In-hye y el rescatista Ji-goo se adentran en la ciudad para obtener una muestra de sangre del "paciente cero", una parte crucial de la investigación para tratar de fabricar una vacuna".

\section{Enlaces:}

https://www.imdb.com/title/tt2351310/ ?ref_=ttpl_pl_tt 
https://www.filmaffinity.com/es /film695844.html

Tráiler español

93 días

La película dirigida en 2016 por Steve Gukas, titulada 93 Days / 93 días, (Foto 6) se centra en los sacrificios hechos por los hombres y mujeres que arriesgaron sus vidas para asegurarse de que el virus de Ébola fue contenido, antes de convertirse en una epidemia, cuando se importó en Nigeria por un diplomático estadounidense de Liberia.

Título original: 93 Days.

País: Nigeria.

Año: 2016.

Director: Steve Gukas.

Música: George Kallis.

Fotografía: Yinka Edward.

Guion: Paul S. Rowlston.

Intérpretes: Bimbo Akintola, Danny Glover, Somkele Idhalama, Bimbo Manuel.

Duración: 118 minutos.

Idioma original: inglés.

Género: drama.

Productoras: Distribuida por Natives Filmworks

Sinopsis: Trabajadores de la salud realizan todos sus esfuerzos por contener un brote mortal de ébola cuando un hombre con síntomas llega a Lagos, ciudad portuaria ubicada en las costas de Nigeria que cuenta con más de 20 millones de posibles víctimas. La película muestra a los héroes de la tragedia y su victoria sobre una situación aterradora. Una verdadera trama de relaciones entre el aparato gubernamental, los expatriados de salud pública y los funcionarios médicos. Los protagonistas Patrick Sawyer, un ciudadano estadounidense-liberiano de 42 años contagiado por el virus del Ébola, que aterriza en Lagos en julio de 2014, y la doctora Ada Igonoh, del First Consultant Hospital, que se infecta al tratar a Sawyer.

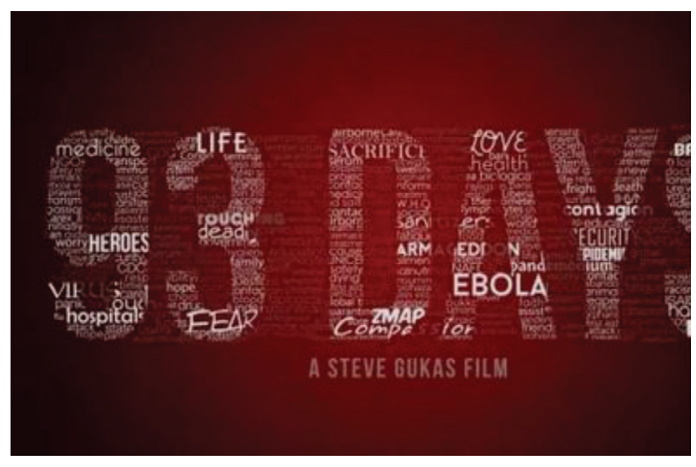

Enlaces:

https://www.imdb.com/title/tt5305246

https://www.netflix.com/es/title/81172895 Tráiler

\section{Llega de noche}

Una película más reciente, estadounidense, con el título It Comes at Night / Llega de noche (2017) (Foto 7) dirigida por Trey Edward Shults. En esta película, una pandemia de origen sobrenatural está asolando el planeta, y las personas sanas tratan de huir a zonas aisladas para evitar la enfermedad. En la película, un hombre que vive en una cabaña con su esposa y su hijo, no se frenará ante nada para proteger a su familia de una presencia maldita que les atemoriza desde el exterior de su casa. Una noche un hombre llega a la casa, y tras asegurarse de que no está infectado, aceptan acogerle a él, a su mujer y a su hijo pequeño. En un principio, todos colaboran para mantener la casa segura. Pero muy pronto empiezan a suceder cosas extrañas, y la enfermedad afecta a algunos de los miembros de las familias.

Título original: It comes at night.

País: Estados Unidos.

Año: 2017.

Director: Trey Edward Shults.

Música: Brian McOmber.

Fotografía: Drew Daniels.

Montaje: Trey Edward Shults, Matthew Hannam. 


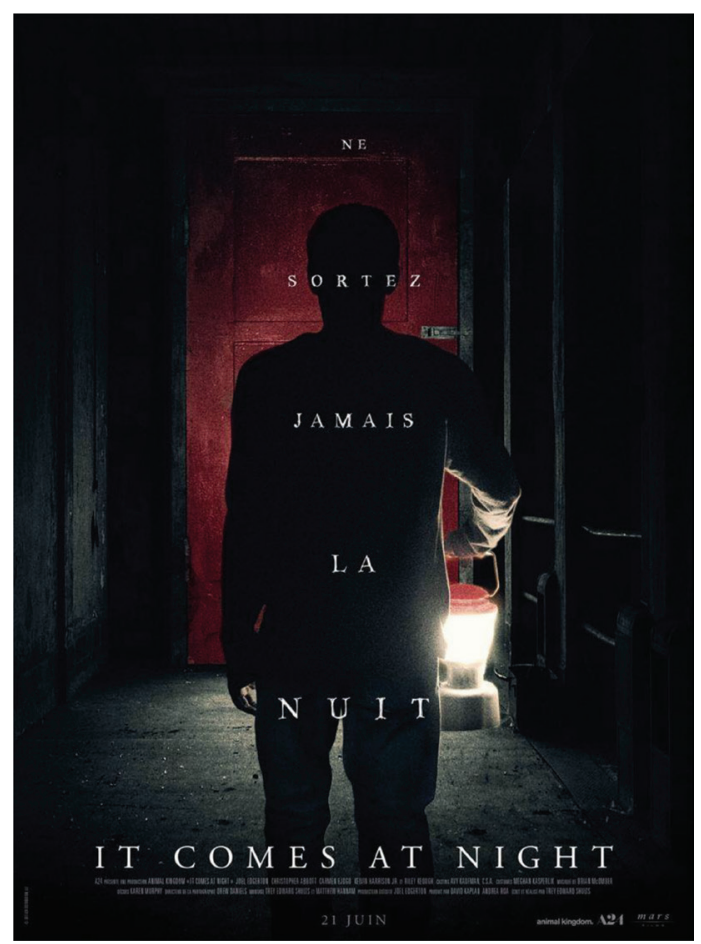

Guion: Trey Edward Shults.

Intérpretes: Joel Edgerton, Christopher Abbott.

Duración: 91 minutos.

Idioma original: inglés.

Género: intriga. terror. thriller.

Productoras: Animal Kingdom, A24.

Sinopsis: Dos familias se alían para combatir contra una presencia maligna que los asedia desde el exterior de la vivienda después de que un misterioso apocalipsis ha diezmado a la población mundial. Paul es un padre de familia que vive en una casa de madera en el bosque con su esposa Sarah y su hijo Travis y que no se frenará ante nada para proteger a su familia de una amenaza que aterroriza al mundo exterior. La película de alta intriga y terror de terror cuenta las peripecias de esta familia que tiene que sobrevivir a base de encierro y desconfianza a un virus del que apenas se tienen detalles, saliendo al exterior siempre protegidos de máscaras y guantes.

\section{Enlaces:}

https://www.imdb.com/title/tt4695012/

https://www.espinof.com/criticas/llega-de -noche-paranoia-e-infeccion-entre-tinieblas http://www.sensacine.com/peliculas /pelicula-237947/criticas-espectadores/

Tráiler

La lista de películas con esta trama podría hacerse mucho más extensa; así por ejemplo otras películas en esta línea, que solamente citaremos, es la titulada Estallido o Epidemia / Outbreak (1995), de Wolfgang Petersen, es película la más cercana al brote de ébola de 2015, o Mimic (1997), de Guillermo Del Toro, en la que muestra un futuro no muy lejano en que Nueva York es atacada por un brote epidémico, provocado por las cucarachas, que amenaza con la muerte a todos los niños.

Otras películas como Doce monos / 12 Monkeys (1995), de Terry Gilliam, ambientada en el año 2035, se sitúa después de una epidemia provocada por un virus asesino que ha matado a millones de personas. Los supervivientes se refugian en comunidades subterráneas, húmedas y frías. El protagonista es un prisionero que se ofrece como voluntario para viajar al pasado y conseguir una muestra del virus, gracias a la cual los científicos podrán elaborar un antídoto. O la película El puente de Cassandra / The Cassandra crossing (1976), de George Pan Cosmatos que narra la historia de los intentos de supervivencia de unos pasajeros que se están atrapados en un tren afectado por un virus mortal.

La lista de títulos es interminable; así por ejemplo otras películas como: La amenaza de Andrómeda / The Andromeda strain (1971) de Robert Wise; Exterminio / Fukkatsu no hi (1980) de Kinji Fukasaku, La peste (1992) de Luis Puenzo; El fin de los tiempos/The happening (2007) bajo la dirección de M. Night Shyamalan, Ceguera / 
Blindness (2008) de Fernando Meirelles; Tren a Busan / Train to Busan (2016) de Yeon Sang-ho; El final de los sentido s/ Perfect Sence (2011) de David Mackenzie; Cargo (2017) de Ben Howling y Yolanda Ramke; etc., podrían añadirse al gran número de películas editadas con esta trama.

Posiblemente surgirán nuevos títulos de películas, series y documentales relacionadas con esta temática, tras la irrupción en nuestro mundo de la enfermedad conocida como covid19 (coronavirus disease 2019), infección causada por el coronavirus surgido en Wuhan (China) en diciembre del año pasado.

\section{CONSIDERACIONES FINALES}

La vigilancia epidemiológica, el establecimiento de programas de alerta temprana, la utilización de los mejores recursos humanos de diversas categorías, etc., permitirán trabajar de una forma coherente, en la prevención y restablecimiento de estas patologías desde un enfoque multidisciplinar. En este sentido la industria cinematográfica, puede contribuir, mediante diversas películas, a una sensibilización de la población mundial y poder difundir y promover medidas higiénico-sanitarias a tomar, ante estas situaciones de pandemias. Es por tanto indispensable, si se quiere controlar la aparición de nuevas pandemias, desarrollar planes multidisciplinarios de prevención y control; buenos sistemas de comunicación a la población y aplicar oportunamente las medidas necesarias para mitigar, en la medida de lo posible, los efectos de estas pandemias.

La Organización Mundial de la Salud, así como diversas agencias nacionales e internacionales, trabajan conjuntamente para elaborar estrategias que permitan implantar medidas preventivas, incluyendo nuevos métodos diagnósticos, modernas drogas antivirales, y sobre todo en la elaboración de nuevas vacunas, que curen estas enfermedades virales.

El cine es un recurso muy útil y positivo que nos ayudan a comprender mejor las patologías y sus prevenciones, así como a divulgar las estrategias que marcan las organizaciones sanitarias. La popularidad que tiene el cine hace de él una herramienta muy válida en la transmisión de conocimientos sobre diversas patologías, sus pautas de comportamiento antes las mismas, y las medidas terapéuticas a seguir.

\section{REFERENCIAS}

1. Barnes E. Diseases and human evolution. Albuquerque: University of New Mexico Press, 2007.

2. Eldredge N. La vida en la cuerda floja. La humanidad y la crisis de la biodiversidad. Barcelona: Tusquets Editores: 2001

3. Vera Bolaños M. Revisión crítica a la teoría de la transición epidemiológica. Pap Pobla. 2000; 6(25): 179-206.

4. World Health Organization. Blueprint for R\&D preparedness and response to public health emergencies due to highly infectious pathogens. Workshop on prioritization of pathogens. Geneva, 15 December 2015.

5. Uribe-Corales N. Algunas pandemias en la humanidad. Una mirada a sus determinantes. CES Salud Pública. 2015; 6(1): 89-93.

6. Murray KA. Preston N, Alen T. Zambrana-Torrello C. Hosseini PR. Daszak P. Global biogeography of human infectious diseases. Proc Natl Acad Sci USA. 2015; 112(41): 12746-51. 


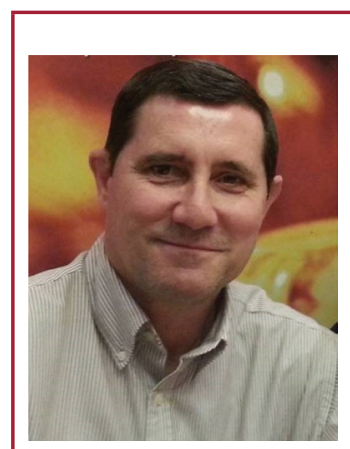

Profesor Dr. Juan A. Juanes Méndez.

Facultad de Medicina.

Responsable del GIR VisualMed Systems.

Universidad de Salamanca.

Miembro del Panel de Expertos del Programa ACADEMIA (Rama Ciencias de la Salud), del Programa para la Acreditación Nacional para Profesores Titulares de Ciencias de la Salud, de la Agencia Nacional de Evaluación de la Calidad y Acreditación (ANECA).

Miembro del panel de expertos de la EQA (Europena Quality Assurance). Galardonado con más de diez premios en diferentes ediciones del Certamen Internacional de Cine Médico. 